\title{
Should We Have or Should We Have Not, and Who Should Have Paid?
}

\author{
Benjamin Bental ${ }^{*}$ and Dominique Demougin
}

March 1, 2011

\begin{abstract}
We analyze an overlapping generations model which explicitly includes a secondary asset market. The economy is affected by a onetime shock which causes some of these assets to become toxic. As a response the government may intervene by buying these assets at market value and removing them from trade. When the shock is not anticipated we find that government intervention cannot improve upon the laissez-faire equilibrium. However, when agents anticipate that a crisis may occur, removing the toxic assets dominates laissez-faire, particularly when the toxic asset holders are financing the intervention scheme. Finally, we show that curbing incentives which drive investors to find high yield opportunities decreases the severity of a crisis once it occurs, but also output.
\end{abstract}

JEL E44, E61

Keywords Crisis, Toxic Assets, Intervention

\section{Introduction}

The recent crisis was a crisis of the financial sector. At some point assets that were regarded as "safe" turned out to be risky. More importantly, the complicated financial structures that have developed over the last decade

${ }^{*}$ Department of Economics, University of Haifa, Haifa, Israel and Department of Governance and Economics, EBS University, Wiesbaden, Germany, e-mail: bbental@econ.haifa.ac.il

$\dagger$ Department of Governance and Economics, EBS University, Wiesbaden, Germany and Univertsity Paris 2 Panthéon Assas, e-mail dominique.demougin@ebs.edu

${ }^{\ddagger}$ We thank the DFG for financial support through the Mercator Program. 
or so made it next to impossible to separate the "good" assets from the "toxic" ones. As a result, financial markets collapsed and the crisis has quickly become "real". ${ }^{1}$ In response to these developments a plethora of government programs have been developed. ${ }^{2}$ Some of these programs aimed at removing "troubled assets" from the market. The idea was to "clean up" the balance sheets of financial institutions and restore confidence in the financial markets. ${ }^{3}$ The programs have all been financed through debt, clearly implying shifting the burden to future generations.

The policy of buying toxic assets has encountered strong criticism claiming that the money is being wasted. ${ }^{4}$ Moreover, there is a prevailing sense that intervention induces moral hazard. In other words, while intervention might have been justified due to the surprise nature of the current crisis, dynamic considerations suggest that it should not be used in the future to avoid moral hazard. This sentiment is quite explicit in President Obama's speech at Wall Street on the first anniversary of the Lehman Brothers bankruptcy, where he said: "Those on Wall Street cannot resume taking risks without regard for consequences, and expect that next time, American taxpayers will be there to break their fall." ${ }^{5}$ In addition, many countries have moved to limit boni in the financial sector as an attempt to further reduce opportunistic behavior.

The purpose of our paper is to address the above questions. We construct a model in which secondary asset prices collapse due to a crisis. While the occurrence of the crisis is taken to be exogenous, it is assumed to generate toxic assets. We consider government programs removing these assets from trade thereby restoring confidence in the market. We distinguish between two scenarios and two financing schemes. In the first scenario the crisis comes as a complete surprise while in the second it is stochastically anticipated. The

\footnotetext{
${ }^{1}$ There is an immense body of literature discussing the events leading to the crisis. For a succinct overview see Blanchard (2009).

${ }^{2}$ The St. Louis Fed provides a chronological list of events and governmental programs that have been implemented in the U.S. since 2007. See http://timeline.stlouisfed.org/index.cfm?p=home. For an international survey of the events see, e.g. Goddard et al (2009).

${ }^{3}$ The goals of the program may be found in http://www.ustreas.gov/press/releases/hp1150.htm For details of the program, see http://www.federalreserve.gov/bankinforeg/tarpinfo.htm

${ }^{4}$ The U.S. Congress has appointed an oversight panel to monitor the Troubled Asset Releif Program (TARP). The February 2009 report of that panel pointed out that "Treasury paid substantially more for the assets it purchased under the TARP than their then-current market value." See http://cop.senate.gov/documents/cop-020609-report.pdf

${ }^{5}$ http://www.huffingtonpost.com/2009/09/14/obama-wall-streetspeech_ n_285841.html
} 
program is either financed by current asset holders or by future generations. We find that in terms of the economy's output, the usefulness of the program depends on the combination of these features. When the crisis comes as a complete surprise removing toxic assets is at best useless and may even be harmful if financed by future generations. On the other hand, should the crisis be stochastically anticipated, intervention financed by current asset holders is beneficial while it is detrimental if financed by future generations. Finally, considering policies aimed at reducing opportunistic behavior, we find that they are associated with a tradeoff between the severity of the crisis and the average level of output.

Formally, we use an overlapping generations model to focus on trade in financial assets. Abstracting from the complexities of financial intermediation in our framework, financial assets are traded directly in competitive markets. Within this setup, we consider an exogenous shock that wipes out the underlying value of some of these assets, creating a "lemons problem".

To understand the modeling idea, consider an overlapping generations environment which combines the basic structure proposed by Diamond (1965) with renewable capital and a Lucas "tree economy" (Lucas 1978). Moreover, capital outlives agents thereby giving rise to secondary asset markets (see Bencivenga, Smith and Starr 1996). Specifically, agents are two period-lived. When young they are endowed with one unit of labor, but want to consume in both periods of their lives. Output consists of "apples" which grow on "trees". Apples may be either consumed or planted. Apples planted in the current period turn into fruit-bearing trees in the following two periods and die afterwards. Thus, investment in trees remains productive for a longer duration than the life of the generation that has initially planted them.

The "apple industry" consists of profit-maximizing "firms" which operate in a competitive environment. These firms operate one of two tree-growing technologies; a low and a high yield technology where the latter is riskier. At each period newly created firms issue shares to raise "capital" which is used to purchase apples (from the current young) and plant them. Shares represent claims on the future profits generated by the respective firms. In the following period these firms require labor supplied by the young to work in the "orchard". The firms pay competitive wages and allocate dividends to their current owners. These owners (the current old) sell their shares (i.e., claims on the profits to be generated by firms in the consecutive period) to the current young. The current old consume the proceeds of these sales, and the dividends they receive according to their share ownership. The current young allocate their wage-income to consumption and saving both in shares of existing firms through the secondary asset market and in newly issued shares sold on the primary market. However, the latter market consists of 
firms with different yields and the young also invest resources in order to search for the best investment opportunities.

To capture the idea of a "crisis" we assume that the economy is initially in steady-state. We introduce a commonly known one-time shock which may come as a surprise (case I) or be stochastically anticipated (case II). When occurring the shock reduces the productivity of all firms (for instance, due to a disease that affects trees) and has an additional impact in the ensuing period. Specifically, some orchards (firms) become sterile and do not bear fruit in the following period (in keeping with the story, farmers of some orchards cannot curb the disease of last period's seedlings). Hence, these orchards have become worthless. In contrast, trees in other orchards are fully cured. While the market knows the fraction of affected orchards, it cannot identify them, thereby creating a "lemons" problem in the secondary asset market. In particular, claims on sterile orchards are "toxic" because they depress the value of the entire secondary market. Furthermore, in order to discuss incentive issues associated with policy, we assume that the mix of technologies emerging from search is related to the severity of the crisis.

The occurrence of a crisis generates an adjustment path of investment, output, consumption, wages and asset prices. We consider two different taxfinanced intervention schemes whereby the government offers to purchase toxic assets at market prices in order to remove them from trade. The first scheme taxes the current old (i.e., asset holders) while the second is financed by the young. We ask whether such schemes can improve the economy's performance along that adjustment path distinguishing between the surprise and anticipated crisis scenarios. In addition we investigate the tradeoffs associated with attempts to affect the incentives to search by conditioning taxes on the outcome of the latter.

Our paper is part of the growing literature discussing the recent crisis. As is well known, what started in the relatively small sub-prime sector in the U.S. has quickly affected the global economy (see e.g. Blanchard 2009, Demyanyk and van Hemert 2008, and Reinhart and Rogoff 2008). Since "toxic assets" could not be easily recognized, counter-party risk could not be assessed and the credit market (particularly the inter-bank loan market) collapsed (see Gorton and Metrick 2009). To alleviate this problem and restore confidence, governments introduced programs aiming at cleansing the balance sheets of financial institutions (e.g., the Troubled Asset Relief Program, in the U.S.). There exists evidence that these programs were quite effective (see e.g. Veronesi and Zingales 2010 as well as Bayazitova and Shivdasani 2009). Our analysis is most closely related to the literature which examines the impact of intervention in environments with informational asymmetries (see, e.g., Dang, Gorton and Holmström 2009, Tirole 2010, Uhlig 2009 and 
the literature therein). While the focus of that literature is on liquidity provision, we are mainly interested in the risk-related allocative role of the financial market and the dynamics of the economy within a simple informational structure. ${ }^{6}$

The paper proceeds as follows. Next section introduces the model discussing technology and agents. Section 3 characterizes the dynamic equilibrium. Section 4 specifies an example used in the remainder of the paper. Section 5 describes policies under surprise crisis and a numerical analysis of this case is conducted in section 6 . Section 7 considers an anticipated crisis and provides a numerical analysis. The last section offers some concluding remarks.

\section{The Model}

We consider a discrete-time, overlapping generations model. The economy is populated by a measure 1-continuum of identical two-period lived agents which appear every period. In addition, there is a continuum of firms producing apples referred to below as "orchards". All markets to be described below are perfectly competitive and prices are measured in apples of the current period. To set the stage, we describe first the economy ignoring the possibility of a crisis.

\subsection{Technology}

There are two technologies generating identical trees. Technology 1 turns an "apple" planted at period $t-1$ into a "new tree" at period $t$ which becomes an "old tree" in $t+1$. Technology $\gamma$ only requires a fraction $\gamma<1$ of an apple to generate such a tree. Orchards are generated by one of the two tree-growing technologies. Given an orchard, the production function of apples is orchardage dependent. For new orchards, it is a standard constant returns to scale function given by $F_{s}(q(t-1), \ell(t))$, where $\ell(t)$ stands for labor employed by the orchard, and $q(t-1)$ denotes the number of trees growing in it. Apples grown by old orchards do not require labor. Output is proportional to the number of trees in the orchard, but is also affected by the economy-wide number of trees. Specifically, an old orchard generates $F_{\sigma}(Q(t-2)) q(t-2)$ apples when employing $q(t-2)$ old trees and where $Q(t-2)$ denotes the

\footnotetext{
${ }^{6}$ In fact, based on a micro-study, Kahle and Stultz (2010) argue that the main effect of the crisis was that of increased risk rather than credit contraction.
} 
aggregate number of old trees in the economy, with $F_{\sigma}^{\prime}<0 .{ }^{7}$ Old trees fully depreciate in the process of production.

A new orchard that has planted $q(t-1)$ trees last period generates at period $t$ profits of

$$
D_{s}(t)=F_{s}(q(t-1), \ell(t))-w(t) \ell(t)
$$

where $w(t)$ denotes period- $t$ wages. Profit maximization yields:

$$
w(t)=\frac{\partial F_{s}(q(t-1), \ell(t))}{\partial \ell}
$$

Due to the CRS assumption, it implies that the orchard's total dividends in $t$ are:

$$
D_{s}(t)=\frac{\partial F_{s}(q(t-1), \ell(t))}{\partial q} q(t-1)
$$

Since old orchards do not require labor, total dividends of orchards using trees planted two periods ago are:

$$
D_{\sigma}(t)=F_{\sigma}(Q(t-2)) q(t-2)
$$

To finance the planting of new trees orchards issue shares. Without loss of generality, we normalize a share to represent a claim on the future profits generated by a single tree. Hence, per-share payout of profits becomes:

$$
d_{s}(t)=\frac{\partial F_{s}(q(t-1), \ell(t))}{\partial q}
$$

and

$$
d_{\sigma}(t)=F_{\sigma}(Q(t-2))
$$

To further simplify our presentation and due to the $C R S$ assumption, we impose that the "number" of orchards equals the size of a generation, i.e. measure 1 .

\footnotetext{
${ }^{7}$ Notice that due the $C R S$ assumption, output of the new tree orchards can be written as $F_{s}(1, \ell(t) / q(t)) q(t)$. At the aggregate, there is one unit of labor, and $q(t)=Q(t)$ (hence, the equivalent of $F_{\sigma}^{\prime}<0$ holds also with respect to the new orchard production function since $\left.F_{s \ell}>0\right)$. The specification of the old orchard production function follows the same logic. However, to develop an analytically tractable example we avoid labor allocation issues between the two types of orchards, and assume that the individual producers take the coefficient $F_{\sigma}(\cdot)$ as given. See footnote 9 for further discussion.
} 


\section{$2.2 \quad$ Agents}

Each agent is endowed with one unit of labor in the first period of his life. The preferences of an agent born at period $t$ are given by $U\left(c_{1}(t), c_{2}(t), e(t)\right)=$ $u\left(c_{1}(t)\right)+\beta u\left(c_{2}(t)\right)-e(t)$, where $c_{i}(t)$ denotes the apple consumption by the agent in the $i$ th period of his life, $i=1,2$ and $e(t)$ is search effort.

The young supply labor services perfectly inelastically. The labor income is used for current consumption and for saving. The latter is allocated to purchasing ownership shares in either new or old orchards. From the foregoing, new orchards may be using either tree-growing technology 1, or $\gamma$. Young agents need to invest effort, $e$, in order to search for high-yield orchards (those using the $\gamma$ technology). Given effort, $\lambda(e)$ denotes the likelihood of finding such an orchard, with $\lambda^{\prime}(\cdot) \geq 0, \lambda^{\prime \prime}(\cdot) \leq 0$. We assume that the outcome of search is private information and is revealed before consumption decisions are made.

Saving of an agent born in $t$ is allocated between shares of new and old orchards, $s(t)$ and $\sigma(t)$ respectively. The price of a newly issued share by an orchard using the low-yield technology is 1 . This follows from the above assumption that each apple generates a single tree, and the normalization that a share is a claim on future profits of a single tree. Obviously successful searchers invest only in high-yield orchards. Hence successful agents pay $\gamma$ per share. The price difference between shares of the two orchard types is maintained by the informational asymmetry.

Let $\xi^{j}$ denote the share price faced by agents. Accordingly, $\xi^{u s}=1$ if the agent's search was unsuccessful and $\xi^{s}=\gamma<1$ if search was successful. Saving can be written as $\xi^{j} s(t)+p(t) \sigma^{j}(t)$ where $p(t)$ is the old orchard share price and $j=u s, s .{ }^{8}$ In the following period agents receive the respective dividends and proceeds from selling assets in the secondary market. Contingent on the outcome of search, an agent born in period $t$ faces the following budget constraints:

$$
\begin{aligned}
& c_{1}^{j}(t)=w(t)-\xi^{j} s^{j}(t)-p(t) \sigma^{j}(t) \\
& c_{2}^{j}(t)=\left[d_{s}(t+1)+p(t+1)\right] s^{j}(t)+d_{\sigma}(t+1) \sigma^{j}(t) .
\end{aligned}
$$

At the portfolio selection stage there are three assets; two in the primary market (orchards using technology 1 and those using technology $\gamma$ ) and one in the secondary market. Observe that by construction the rate of return on

\footnotetext{
${ }^{8}$ The expression for saving rules out an intra-generational loan market where the successful searchers borrow from the unsuccessful ones in order to increase their investment in the high-yield project. In other words, we assume that such a market involves sufficiently high transactions costs. Observe that in the absence of such costs no equilibrium would exist in our framework, see e.g. Grossman and Stiglitz (1980).
} 
$\gamma$-technology trees is higher than that of low-yield new trees. Since there are just two types of investors (successful and unsuccessful searchers) all three types of assets can only be held in equilibrium if returns are equalized between two of them. In the remaining we focus on the natural case where successful agents solely invest in high-yield new trees, while the unsuccessful hold a portfolio of both low-yield new trees and old trees. Anticipating the equilibrium where $\lambda$ also measures the fraction of successful searchers, the foregoing restriction implicitly requires that the success rate is not too big. Otherwise, the supply of secondary assets emanating from successful searchers could be sufficiently large to absorb the entire savings of the unsuccessful searchers. In that case, the economy would be in a corner solution with only two assets. From the point of view of our analysis, this case is of no interest since in equilibrium there would be no informational asymmetry.

Accordingly, we obtain the following first-order conditions for the unsuccessful:

$$
\begin{gathered}
-u_{c}\left(c_{1}^{u s}(t)\right)+\beta\left[d_{s}(t+1)+p(t+1)\right] u_{c}\left(c_{2}^{u s}(t)\right)=0 \\
-p(t) u_{c}\left(c_{1}^{u s}(t)\right)+\beta d_{\sigma}(t+1) u_{c}\left(c_{2}^{u s}(t)\right)=0,
\end{gathered}
$$

and for the successful:

$$
-\gamma u_{c}\left(c_{1}^{s}(t)\right)+\beta\left[d_{s}(t+1)+p(t+1)\right] u_{c}\left(c_{2}^{s}(t)\right)=0 .
$$

Clearly, (9) and (10) imply the no-arbitrage condition which equalizes the rates of return of low-yield new trees and old trees:

$$
\frac{d_{\sigma}(t+1)}{p(t)}=d_{s}(t+1)+p(t+1) \text {. }
$$

Finally, the rate of return on high-yield new trees is $\left[d_{s}(t+1)+p(t+1)\right] / \gamma$.

Prior to searching agents anticipate their post-search consumption stream. Hence, we define post-search optimal utility

$$
v^{j}(t)=u\left(c_{1}^{j}(t)\right)+\beta u\left(c_{2}^{j}(t)\right), \quad j=s, u s .
$$

Therefore ex-ante agents equate their respective marginal benefit of search to the marginal cost thereof. Letting $e(\lambda)=\lambda^{-1}(e)$ and omitting the time index it yields:

$$
e^{\prime}(\lambda)=v^{s}-v^{u s}
$$

\section{Equilibrium and Saddle Path}

All young agents are ex-ante identical and arrive at the same search effort choice, generating the same success likelihood. Due to the law of large numbers, $\lambda(t)$ is, therefore, the fraction of successful young agents. Moreover the 
constant returns to scale assumption implies that the number of orchards and their size does not matter.

Altogether, an equilibrium consists of sequences $\left\{\lambda(t), c_{1}^{j}(t), c_{2}^{j}(t-1), \ell^{j}(t)\right.$, $\left.s^{j}(t), \sigma^{j}(t), S^{j}(t), q(t), Q(t), d_{s}(t), d_{\sigma}(t), w(t), p(t)\right\}_{t \geq 1}$ where $S^{j}(t)$ denotes aggregate primary investment for $j=s$, us, and such that, given initial period-1 amounts of aggregate old and new trees, $Q(-1)$ and $Q(0)$, the following hold:

1. All markets clear. Specifically:

$$
\left\{\begin{array}{c}
\lambda(t) s^{s}(t)+(1-\lambda(t)) s^{u s}(t)=q(t)=Q(t) \\
s^{j}(t)=S^{j}(t), j=s, u s \\
(1-\lambda(t)) \sigma^{u s}(t)=q(t-1) \\
\sigma^{s}(t)=0 \\
\ell^{s}(t)=\ell^{u s}(t)=1
\end{array}\right.
$$

2. All agents and firms optimize, taking market prices as given. Specifically, equations (2), (3), (4), (9), (10), (11) and (14) hold.

3. Perfect foresight prevails.

The first equation in (15) captures the market clearing requirement of new trees. The LHS aggregates per-capita (in each generation) investment of successful and unsuccessful agents. The RHS is the per-capita number of trees in the apple production process, $q$, which is also the corresponding aggregate number of trees, $Q$. The second equation identifies individual with per-capita primary investments. The third and fourth equations result from the observation that only the unsuccessful participate in the secondary asset market. Finally the last equation follows from the assumption that leisure has no value.

Applying the equilibrium conditions, we rewrite the wage equation (2), as follows:

$$
w(t)=\omega(Q(t-1)) .
$$

It implies that the income of the young depends solely on aggregate amount of new trees. In addition, we denote the equilibrium marginal product of new trees (which is also the dividend per tree) by:

$$
\frac{\left.\partial F_{s}(Q(t-1), 1)\right)}{\partial q}=\mu(Q(t-1)) .
$$

Using the equilibrium conditions and applying (16) and (17) to (9), (11) and (12) yields a dynamic system which can be reduced to a pair of first order difference equations in $Q(t-1), Q(t), p(t)$ and $p(t+1)$. 
As is usually the case in such environments, this system has only one initial condition, $Q(t-1)$. Absent further restrictions, it is indeterminate. In order to uniquely determine the equilibrium path we assume that the dynamic system satisfies the saddle path property, which imples that the state variable $Q(t-1)$ determines not only $Q(t)$, but also $p(t)$. Put differently, under this condition, there exists a pricing function

$$
p(t)=P(Q(t-1))
$$

so that the single initial condition becomes sufficient to generate a unique equilibrium path. ${ }^{9}$

In general, however, the pricing function (if it exists) cannot be characterized analytically. A standard approach requires linearizing the above system and approximating the pricing function locally around the steady-state. However, this approach is not capable of answering some of the questions we ask below. ${ }^{10}$ Instead, in the remaining we turn to an analytical example and explicitly solve for the pricing function.

\section{A Specified Example}

In the remaining of the paper we use a specified economy for which the pricing function is analytically computable from the underlying preferences and production functions. In particular, we use the following functional forms:

- Preferences: $u(c)=\ln (c)$,

- Effort cost: $e(\lambda)=\kappa_{0}+\kappa_{1} \lambda+\frac{1}{2} \kappa_{2} \lambda^{2}$,

- New-tree technology: $F_{s}(q, \ell)=A q^{\alpha} \ell^{1-\alpha}, 0<\alpha<1$,

- Old-tree technology: $F_{\sigma}(Q)=\Psi Q^{\alpha^{2}-1}$.

\footnotetext{
${ }^{9}$ The restrictions on the technology generating apples from old trees reduce the dimensionality of the state-space and enable us to provide an analytically tractable example. A more general specification would have included labor in that technology as well, e.g. $F_{\sigma}\left(q(t-2), \ell_{\sigma}(t)\right)$. This would require labor to be allocated between the two technologies, and the equilibrium wage would depend on both $Q(t-2)$ and $Q(t-1)$. Consequently the pricing function would also depend on these state variables. Unfortunately, we could not find a specification of this form generating an analytical solution for the pricing function.

${ }^{10}$ In particular, when the crisis is anticipated, the economy's path prior to the crisis differs from the post-crisis one. By construction, a linearization around the steady-state cannot capture this difference.
} 
For this specification the dynamic system is characterized by the following set of equations:

$$
\left\{\begin{array}{c}
S^{u s}(t)+\frac{p(t) Q(t-1)}{1-\lambda(t)}=\frac{\beta}{1+\beta} \omega(Q(t-1)) \\
S^{s}(t)=\frac{\beta}{\gamma(1+\beta)} \omega(Q(t-1)) \\
\frac{F_{\sigma}(Q(t-1))}{p(t)}=\mu(Q(t))+p(t+1) \\
\lambda(t) S^{s}(t)+(1-\lambda(t)) S^{u s}(t)=Q(t)
\end{array}\right.
$$

together with the appropriate condition for the choice of effort.

Lemma 1 For the above specification, search effort is a constant solving

$$
e^{\prime}(\lambda)=-\beta \ln (\gamma)
$$

Proof. For above specification, (14) becomes:

$$
e^{\prime}(\lambda)=\ln \left(\frac{c_{1}^{s}}{c_{1}^{u s}}\right)+\beta \ln \left(\frac{c_{2}^{s}}{c_{2}^{u s}}\right) .
$$

Since the logarithmic preferences imply that saving is a constant fraction of income, $c_{1}^{s}=c_{1}^{u s}$. Moreover, the rate of return for successful searchers is higher than that of their unsuccessful counterpart by the factor of $\frac{1}{\gamma}$. Hence $\frac{c_{2}^{s}}{c_{2}^{\text {us }}}=\frac{1}{\gamma}$ verifying the claim.

Notice that in (19) the first two equations follow from (9) and (11), the third is the no-arbitrage condition (12) and the last one results from the equilibrium requirement. Moreover, search effort is time independent. Observe that multiplying the first equation by $(1-\lambda)$, the second by $\lambda$ and adding them (using the equilibrium condition), the entire dynamics of the above system can be captured by:

$$
\left\{\begin{array}{c}
Q(t)+p(t) Q(t-1)=\Lambda \omega(Q(t-1)) \\
\frac{F_{\sigma}(Q(t-1))}{p(t)}=\mu(Q(t))+p(t+1)
\end{array}\right.
$$

where $\Lambda=\frac{\beta}{1+\beta}\left[\frac{\lambda}{\gamma}+(1-\lambda)\right]$. The saddle path property implies $p(t)=$ $P(Q(t-1))$ and $p(t+1)=P(Q(t))$. Accordingly the system (22) consists of two first-order difference equations both in $Q(t)$. Hence both equations must be identical. This imposes restrictions on the pricing function which allow us to solve for $P(\cdot)$. 
Proposition 2 For the above specification the equilibrium pricing function is given by

$$
P(X)=\nu X^{\alpha-1},
$$

The resulting dynamic system satisfies:

$$
Q(t)=\Omega Q(t-1)^{\alpha}
$$

where $\nu$ and $\Omega$ depend on the underlying parameters.

Proof. See Appendix.

Notice that the dynamic relationship obtained here is of the same shape as that obtained in the basic Solow (1956) model with a Cobb-Douglas production function, or the Diamond (1965) model with Cobb-Douglas production and logarithmic preferences.

\section{Surprise Crisis and Policies}

We start by considering a surprise crisis and assuming that the system is initially in its steady-state (where "*" denotes variable in steady-state). At some point $\tau$ a one-period shock occurs that reduces the productivity of all orchards by $0<\zeta<1$. In addition, at $\tau+1$ the orchards which originated from the high-yield growing technology of period $\tau-1$ become sterile. In contrast, the remaining orchards are unaffected in $\tau+1$, still generating $F_{\sigma}\left(Q^{*}\right)$ apples per tree. ${ }^{11} 12$

The occurrence of the shock and its implications are common knowledge at the beginning of period $\tau$ (i.e. before any period $\tau$ decisions are undertaken). Moreover, at period $\tau$ shareholders know whether their orchard will be sterile at $\tau+1$ since they know whether the high-yield technology has been used to grow them. In contrast, buyers of secondary market assets cannot identify the shares associated with sterile orchards (keep in mind that the tree growing technology is private information). Due to the absence of

\footnotetext{
${ }^{11}$ Alternatively, we could specify that old trees generate $F_{\sigma}((1-\zeta) Q(t-1))$ apples without significantly affecting the conclusions. The chosen structure allows us to concentrate on the "net-effect" of the shock on the secondary asset market ignoring additional implications due to secondary productivity effects.

${ }^{12}$ The extreme asymmetric treatment of the two types of orchards is intended to capture a salient characterisitc of the recent financial crisis. The high yield instruments developed by the financial industry all collapsed at the same time due to their instrinsic interrelationship. Commenting on this feature of the financial sector, Cochrane (2009) has expressed the idea succintly as follows : ".... it turns a "smooth" risk, like equities, which are repriced routinely, into "earthquake" risk that either pays a steady stream or fails catastrophically and unpredictably....".
} 
other transactions costs, we assume they buy a "market portfolio" carrying the average payoff.

In the sequel we examine the dynamic repercussions of the shock on the equilibrium path, considering two policy scenarios. In the first, we let the market absorb the shock while in the second, we analyze public intervention schemes.

The No Intervention Case: Due to the shock, period $\tau$ wages are reduced to $\omega\left((1-\zeta) Q^{*}\right)$. Moreover, the average output per old tree at period $\tau+1$ becomes $(1-\hat{\lambda}) F_{\sigma}\left(Q^{*}\right)$ where $\hat{\lambda}$ is the fraction of high-yield trees given by $\lambda S^{s *} / Q^{*}$. These changes affect the secondary market price, $p(\tau)$, and investments in the primary market, $Q(\tau) \cdot{ }^{13}$ Once the latter has been determined the entire future path of the economy can be generated from the saddle path property using (22). However, the value of $Q(\tau)$ (and of $p(\tau)$ ) cannot be determined without knowledge of $p(\tau+1)$. This feedback requirement is closed by the pricing function and the perfect foresight condition. It yields a system analogous to (19) for the crisis period $\tau$. Altogether, the system determining $Q(\tau)$ and $p(\tau)$ can be summarized by

$$
\left\{\begin{array}{c}
Q(\tau)+p(\tau) Q^{*}=\Lambda \omega\left((1-\zeta) Q^{*}\right) \\
\frac{(1-\hat{\lambda}) F_{\sigma}\left(Q^{*}\right)}{p(\tau)}=\mu(Q(\tau))+P(Q(\tau)) .
\end{array}\right.
$$

The Intervention Case: We now assume that a public authority intervenes by offering to purchase shares of sterile orchards (hereafter toxic assets) removing them from future trade. The public tender is made at market prices. We assume that shareholders of toxic assets accept the public tender since they have no disadvantage from doing so; from the foregoing, they have the relevant information and they sell at market price.

The intervention scheme is financed by lump-sum taxes. The cost of the program is $T(\tau)=\hat{\lambda} p(\tau) Q^{*}$. Letting $\phi$ denote the fraction of this cost paid by the young, their tax amounts to $T_{1}(\tau)=\phi T(\tau)$. The equilibrium period- $\tau$ saving and no-arbitrage conditions become:

$$
\left\{\begin{array}{c}
Q(\tau)+p(\tau)\left[(1-\hat{\lambda}) Q^{*}\right]=\Lambda\left[\omega\left((1-\zeta) Q^{*}\right)-T_{1}(\tau)\right] \\
\frac{F_{\sigma}\left(Q^{*}\right)}{p(\tau)}=\mu(Q(\tau))+P(Q(\tau)) .
\end{array}\right.
$$

As of period $\tau+1$ the equilibrium follows from the saddle path property.

\footnotetext{
${ }^{13}$ Observe that search effort remains unaffected for the same reasons as in Lemma 1.
} 
The equation systems (25) and (26) emphasize the three relevant aspects of intervention. First, by removing toxic assets, intervention reduces the stock of old trees traded in the secondary market ( $L H S$, first equation). Second, intervention involves taxation reducing disposable income of the young ( $R H S$, first equation). Finally, by removing toxic assets, intervention increases the rate of return in the secondary market ( $L H S$, second equation).

Lemma 3 An intervention (INT) fully taxing the old leads to the same adjustment path as that of the no-intervention (NO) case except for a onetime secondary market price difference at period $\tau$, given by $p^{I N T}(\tau)(1-\hat{\lambda})=$ $p^{N O}(\tau)$.

The result of this lemma is straightforward since under either policy the old fully carry the loss and the young obtain the average output in the following period. However, Lemma 3 does not contain any information on the relative merit of different tax schemes.

\section{Numerical Analysis of a Surprise Crisis}

This section uses a numerical example to provide an intuition on the economy's adjustment path under two extreme tax schemes either levying the tax solely on the old or on the young. For the purpose of this experiment, we choose the following parameter values:

\begin{tabular}{lll}
\multicolumn{3}{c}{ Table 1: Parameter Values } \\
Variable & Symbol & Value \\
Second period weight in preferences & $\beta$ & 0.75 \\
Cost advantage of "high yield" capital & $\gamma$ & 0.8 \\
Productivity of "new" capital & $A$ & 7.8 \\
Output elasticity of "new" capital & $\alpha$ & 0.3 \\
Productivity of "used" capital & $\Psi$ & 2.7 \\
Crisis probability & $\pi$ & 0.2 \\
Tax share of the young & $\phi$ & 0 or 1
\end{tabular}

At steady-state, these parameter values yield an investment rate of 0.14 (out of total output), and a rate of return for the unsuccessful searchers of 2.34. The latter should be interpreted with caution, since the association between a "period" in this model and "real" time is not straightforward. The 
value of $\Psi$ was obtained by setting the steady-state value of $\nu$ (the coefficient of the pricing function) to $1 .^{14}$

While we make no claim of having "calibrated" the model, we want to emphasize that the chosen parameters are "reasonable" if we choose to treat a "period" as representing ten years. To get some feeling, an accumulated return of 2.34 is obtained by annualizing an interest rate of $8.8 \%$ over ten years. Similarly, it takes about ten years to compound a yearly discount factor of 0.97 (commonly used in RBC models) into 0.75. A crisis probability of 0.2 per period is equivalent to a yearly crisis probability of 0.025 over ten years.

The results depicted below focus on aggregate investment in new trees, secondary asset prices, aggregate saving of the young and total output. The no-intervention case is represented in Figure 1 as percentage deviations from the corresponding steady-state values. As expected, total output decreases when the shock hits, due to the negative impact on productivity. In the following period the shock persists because some of the old trees are sterile. The latter effect is mitigated due to the increased investment in the previous period. At the crisis the productivity shock reduces wages and hence saving. Next period wages and saving increase, due to the increased investment.

\footnotetext{
${ }^{14}$ The relationship between $\Psi$ and $\nu$ is given in the Appendix.
} 

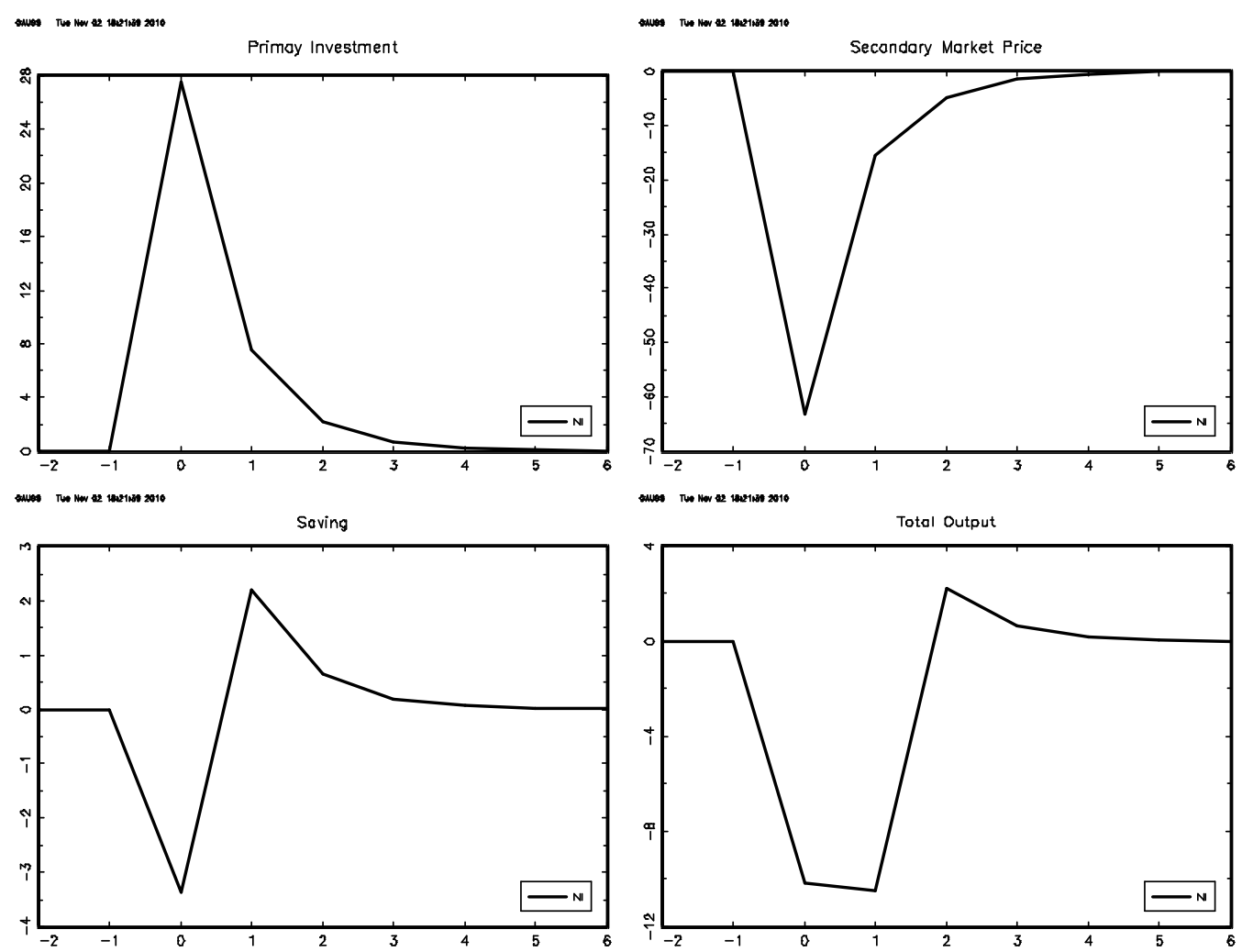

Figure 1: Surprise crisis with no intervention

The sharp decrease of secondary asset prices during the crisis reflects the effect of the "toxic orchards". Finally, primary investment is influenced by a saving and a rate of return effect. The saving effect has already been shown to be negative. With respect to the second effect, the crisis implies a decline in the return of secondary assets making primary assets more attractive. This effect shifts the portfolio composition of the unsuccessful searchers in favor of the latter. In addition, search incentives increase since the rate of return for successful searchers remains unaffected. In our numerical example the latter effects dominate thus raising investment.

Notice that the behavior of investment is driven also by the fact that in our specification the information about the onslaught of a crisis and the end of the crisis arrive at the same moment in time. Separating the two events would generate a lasting investment depression, until that time when the crisis is known to have come to an end. 

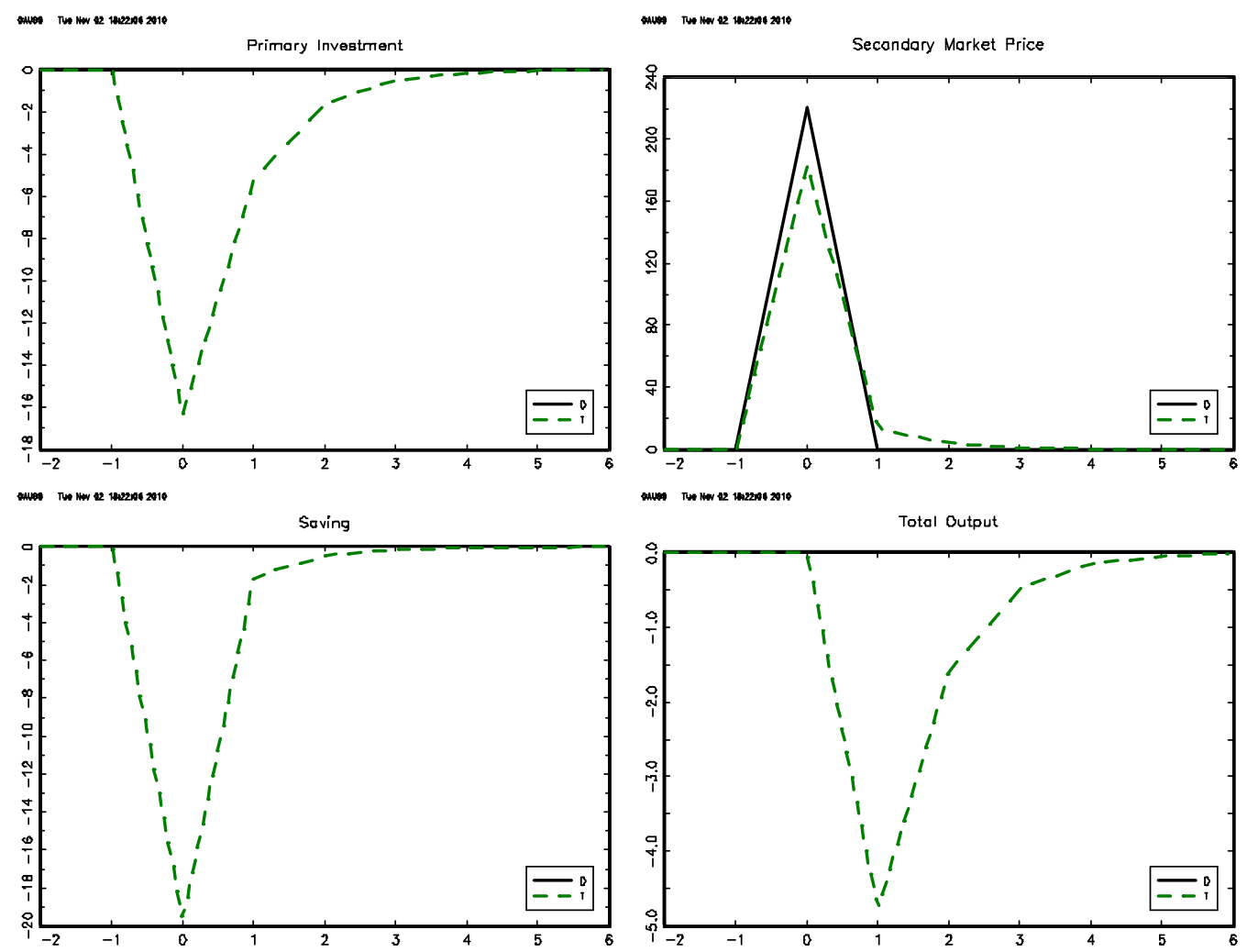

Figure 2: Intervention vs. No-Intervention: Surprise Crisis

The intervention regimes are shown in Figure 2 in terms of relative deviations from the corresponding no-intervention values at the same period. The solid line represents taxing the old $(\phi=0)$ and the dashed one corresponds to taxing the young $(\phi=1)$. In accordance with Lemma 3 , in the former case all real variable follow an identical path as under no-intervention while the secondary asset price adjusts upwards, reflecting the removal of the "toxic orchards".

In contrast, taxing the young adversely affects the real variables. Intuitively, the young's disposable income decreases, thereby decreasing saving. Moreover the return on the secondary asset is increased since the sterile old orchards have been removed. Both effects decrease the demand for primary assets thereby reducing investment in new orchards. This in turn causes next period's output to decrease compared to the no-intervention case. Consequently, adjustment back to the steady-state is slower. The impact of taxing the young on the price in the secondary market at period $\tau+1$ is positive, albeit smaller than that obtained when taxing the old. This follows directly 
from reducing the young's disposable income. However, in the ensuing periods prices are higher because the marginal return to capital remains higher throughout the adjustment path relative to the no-intervention case.

\section{Anticipated Crisis, Policies and Numerical Analysis}

In this section we assume that the crisis is probabilistically anticipated. Specifically, young agents expect a crisis to occur next period with probability $\pi$. Furthermore, they already know which corresponding policy will be enacted. To simplify the analysis, we maintain the assumption that the crisis is a one-time shock. This assumption allows us to invoke the saddlepath property for the post-crisis dynamics and obtain the exact same pricing function as in the foregoing analysis, see equation (23). ${ }^{15}$ In particular, the economy's behavior as of period $\tau$ and onwards is solely determined by the initial condition, $Q(\tau-1)$ and the policy regime.

We also maintain the assumption that prior to the crisis, the economy is on a stationary path. However, in contrast to the surprise case, the anticipation of the crisis and the corresponding policy affect the initial stationary state of the economy including $Q(\tau-1)=Q^{* *}$ (where "**" characterize variable in the pre-crisis stationary path). Due to the anticipation of the crisis, the decision problem of agents prior to the crisis takes into account the possibility of the crisis and its ramifications. Hence, the model implies that the pre-crisis stationary state and the post-crisis dynamic path are co-determined and depend on the policies.

Applying backward induction to the optimization problem of the young, consider the consumption and saving decisions after the realization of the search outcome. Generically agents maximize expected utility given by $v^{* *}=$ $\ln c_{1}^{* *}+\beta\left[(1-\pi) \ln c_{2}^{* *}+\pi \ln c_{2}(\tau)\right]$ subject to success-related budget constraints:

$$
\left\{\begin{array}{c}
c_{1}^{j * *}=w^{* *}-\xi^{j} s^{j * *}-p^{* *} \sigma^{j * *} \\
c_{2}^{j * *}=\left[d_{s}^{* *}+p^{* *}\right] s^{j * *}+d_{\sigma}^{* *} \sigma^{j * *} \\
c_{2}^{j}(\tau)=\left(d_{s}(\tau)+p(\tau)\right) s^{j * *}+d_{\sigma}^{* *} \sigma^{j * *}-T_{2}^{j}(\tau)
\end{array}\right.
$$

where $j=s$, us, $\sigma^{j * *} \geq 0$ and $T_{2}(\tau)=(1-\phi) T(\tau)$. Moving back in the induction process, prior to searching agents anticipate their consumption

\footnotetext{
${ }^{15} \mathrm{An}$ alternative would be to model the shock as a stochastically repeated event and find a corresponding state-dependent pricing function. For a similar approach, see for instance Bental and Eden (1993). As shown above, the simplification allows us to use an analytically derived pricing function thereby avoiding numerical methods to compute the latter.
} 
stream conditioned on the search outcome and the occurrence of a crisis. Accordingly, effort is determined by

$$
e^{\prime}\left(\lambda^{* *}\right)=v^{s * *}-v^{u s * *}
$$

Given a policy, i.e. no intervention or intervention with a corresponding financing scheme, the economy's pre-crisis stationary path is given by a tuple $\mathbb{E}^{1}=\left\{\lambda^{* *}, c_{1}^{j * *}, c_{2}^{j * *}, \ell^{j * *}, s^{j * *}, S^{j * *}, \sigma^{j * *}, \Sigma^{j * *}, \vartheta^{j}, q^{* *}, Q^{* *}, d_{s}^{* *}, d_{\sigma}^{* *}, w^{* *}, p^{* *}\right\}$ where $\Sigma^{j * *}$ denotes the aggregate type dependent secondary asset holding and the multipliers $\vartheta^{j}$ are type dependent to be further defined below. This tuple and the post-crisis path $\mathbb{E}^{2}=\left\{\lambda(t), c_{1}^{j}(t), c_{2}^{j}(t-1), \ell^{j}(t), s^{j}(t), S^{j}(t), \sigma^{j}(t), q(t)\right.$, $\left.Q(t), d_{s}(t), d_{\sigma}(t), w(t), p(t)\right\}_{t \geq \tau}$ define an equilibrium of the economy. These two tuples are interdependent; the post-crisis path depends on the economy's state at period $\tau$, i.e. $Q^{* *}$. The latter is part of the pre-crisis stationary path, which in turn depends on expectations concerning, in particular, the secondary assets price at the crisis, $p(\tau)$.

This complex system can be reduced, in the final analysis, to two variables: $Q^{* *}$ and $p(\tau)$. Depending on the policy, either system (25) or (26) can be used to determine $p(\tau)$ given an initial state $Q^{* *} \cdot{ }^{16}$ On the other hand, given $p(\tau)$, the budget constraints $(27)$ evaluated at market equilibrium, together with the first-order conditions which emerge from the pre-crisis optimization problems, result in a system that determines $\mathbb{E}^{1}$, including $Q^{* *}$. To see this, use the fact that $\ell^{j * *}=1$ and the definitions of $d_{s}^{* *}, d_{\sigma}^{* *}, w^{* *}$, and for $j=s, u s$ write the remaining system as:

$$
\begin{gathered}
-\frac{\xi^{j}}{c_{1}^{j * *}}+\beta\left[(1-\pi) \frac{\mu\left(Q^{* *}\right)+p^{* *}}{c_{2}^{j * *}}+\pi \frac{\mu\left((1-\zeta) Q^{* *}\right)+p(\tau)}{c_{2}^{j}(\tau)}\right]=0 \\
-\frac{p^{* *}}{c_{1}^{j * *}}+\beta F_{\sigma}\left(Q^{* *}\right)\left[(1-\pi) \frac{1}{c_{2}^{j * *}}+\pi \frac{1}{c_{2}^{j}(\tau)}\right]+\vartheta^{j}=0 \\
\lambda^{* *} S^{s * *}+\left(1-\lambda^{* *}\right) S^{u s * *}=Q^{* *} \\
\lambda^{* *} \Sigma^{s * *}+\left(1-\lambda^{* *}\right) \Sigma^{u s * *}=Q^{* *}
\end{gathered}
$$

where the multipliers $\vartheta^{j}$ are associated with $\sigma^{j * *} \geq 0$, so that $\vartheta^{j} \geq 0$ and $\vartheta^{j} \sigma^{j * *}=0$. The variable $\lambda^{* *}$ is given by the solution of (28). While at the micro level $\lambda^{* *}$ captures the individual search effort, at the aggregate it measures the fraction of the young who found the high-yield tree-growing technology. As discussed above, we assume that at the moment of the crisis all high-yield trees are destroyed (see Footnote 12). This captures a much

\footnotetext{
${ }^{16}$ Notice that in Section 3 the initial state was taken to be the economy's steady-state, $Q^{*}$ whereas here it is $Q^{* *}$.
} 
discussed feature of the crisis; while investments in complex financial assets were yielding high return, these were highly correlated.

Equation (29) refers to the $F O N C$ with respect to investments in new trees (primary asset), whereas (30) to the FONC with respect old trees (secondary asset). As we know from the post-crisis path, the successful searchers do not invest in the secondary market. Unless the risk involved in the potential crisis is sufficiently significant, this feature will carry over also into the pre-crisis periods, resulting in $\vartheta^{s}>0$ and $\vartheta^{u s}=0$. Finally, equations (31) and (32) are the respective market clearing conditions for primary and secondary assets. These equation are used to relate $Q^{* *}$ to the individual optimal investment decisions.

Since the crisis is a one-time event, after the crisis has occurred the economy converges to its steady-state. Figure 3 describes the evolution of the relevant variables without intervention as percentage deviations from the steady-state. It illustrates that the pre-crisis stationary path differs from the long-run steady-state. That difference is mainly due to the riskiness associated with the primary asset as next period its price in the secondary asset market may decline, should a crisis take place. This feature generates two effects: it reduces saving and shifts the composition of the portfolio towards the safe asset, namely old trees. Accordingly, while primary investment and output are lower than in the steady-state, secondary assets are priced higher. 

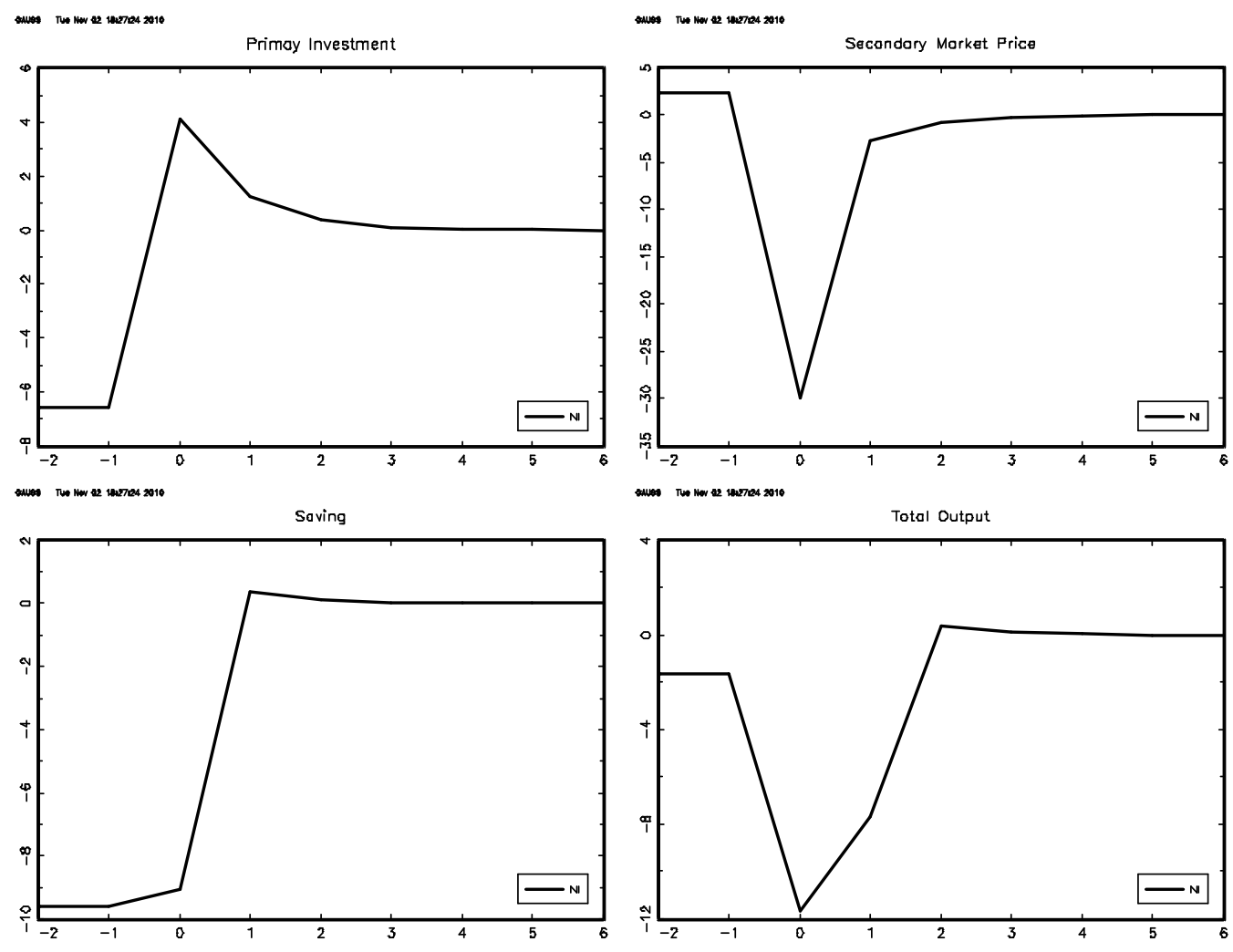

Figure 3: Anticipated Crisis with No Intervention

Figure 4 compares paths of the economy under various intervention schemes to the corresponding no-intervention values (in terms of percentage deviations). We consider three taxation policies that finance the removal of toxic assets from trade; a scheme which only taxes the young (dashed curves), a scheme which taxes the old in a uniform fashion (solid curves) and a scheme which taxes the old differentially, depending upon whether or not they have been successful searchers (solid with inverted triangles). ${ }^{17}$ The third scheme is intended to "privatise the loss" by making those "responsible" for the crisis pay for its consequences.

\footnotetext{
${ }^{17}$ Figure 3 is drawn for the case in which the tax burden of the successful searchers exceeds their share in the population by a factor of 2.5 .
} 

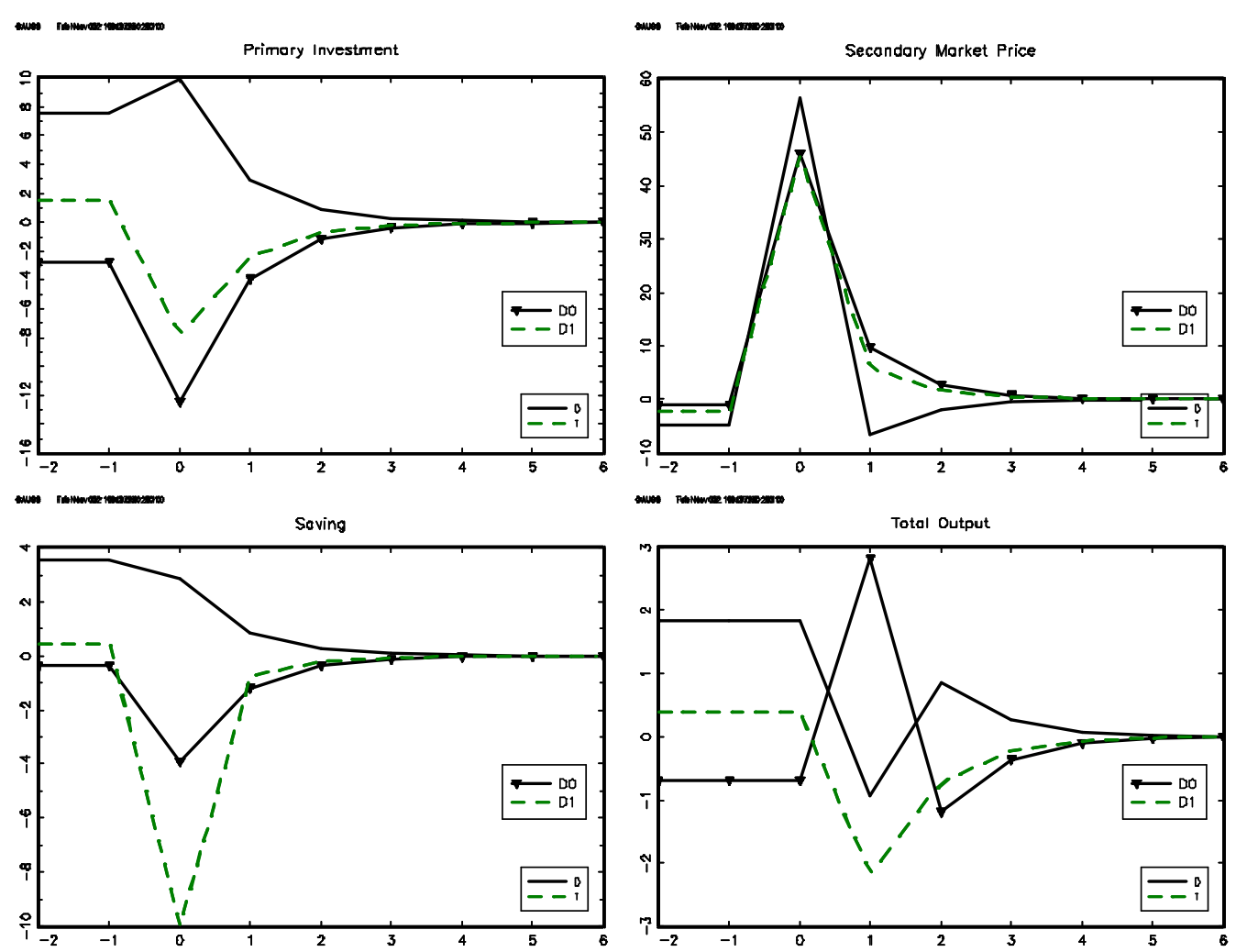

Figure 4: Intervention vs. No Intervention: Anticipated Crisis

First consider the policy which taxes the old uniformly. Since the tax revenue is used to finance the removal of toxic assets, at the crisis the secondary asset price remains high. Hence, prior to the crisis the expected return on investment in primary assets is larger than in the no-intervention case. This boosts the initial stationary path of primary investment, output and savings. It also implies that at the crisis primary investment is higher than in the no-intervention case. In contrast, secondary asset prices are initially lower, reflecting that prior to the crisis the demand for such assets is reduced and the supply increased.

Next, let the tax be imposed on the young. Such a policy reduces their disposable income, lowers saving and hence investment. Secondary asset prices are still higher than in the no-intervention case, but to a lesser extent. Consequently, the impact on pre-crisis primary investment is smaller. In fact, taxing the young in order to finance the intervention, results in an output path that is dominated by the one obtained by the alternative scheme.

The last policy imposes the cost of the intervention mainly on the successful searchers (i.e., those who have invested in assets which became toxic 
at the crisis). Naturally, prior to the crisis this policy reduces the incentive to engage in search (by more than one half relative to equal taxation). Since fewer trees are generated by the high-return technology, the average return on primary investment is reduced. As a result, initial primary investment is the lowest under this policy, and falls even short of the no-intervention case. This effect is also reflected in the lower pre-crisis output level, which in turn is responsible for the lower saving at period $\tau$. In contrast, the lower fraction of trees generated by the high-return technology at the initial path reduces the impact of the crisis on output at period $\tau+1$. This result obtains because fewer orchards are destroyed by the crisis.

\section{Concluding Remarks}

Should we have, or should we have not, and who should have paid? Many think we should have not. Former President Bush has recognized the objection: "a lot of people" became distressed about "spending taxpayer money to give to Wall Street banks to save them" since "they created the crisis in the first place". Nevertheless, Bush believes we should have because "TARP saved the economy". ${ }^{18}$

We find that the answer to the above question is context dependent and, in particular, hinges on the financing scheme of the intervention program. For instance, if we believe that the crisis came as a complete surprise, we conclude that removing toxic assets was at best ineffective and could even be harmful. Specifically, in our numerical example financing the purchase of toxic assets by taxing future generations significantly exacerbates the crisis. In contrast, if the crisis is stochastically anticipated, we find that a government commitment to remove toxic assets should a crisis occur can be beneficial from the point of view of output, in particular, if the program is financed by taxing the assets holder (the "old"). In this sense we find ourselves at some odds with President Obama's statement that "those on Wall Street" should not "expect that next time, American taxpayers will be there to break their fall."

Finally, we address the popular sentiment to make those who "created the crisis in the first place" pay for its consequences. To do so in the model, we impose the bulk of the tax burden associated with the government intervention on the successful searchers. Quite naturally, we find that this policy reduces toxicity in the economy and, thus, mitigates the crisis. However, this comes at the cost of reducing output both prior and after the crisis.

${ }^{18} \mathrm{NBC}$ News interview
http://www.cnbc.com/id/40028600.


While the model is not designed to address other policies like limiting boni, the conclusion suggests that responding to the current episode by policies intended to limit the magnitude of a potential crisis may come at a cost of lowering average output. One should notice that this conclusion, as well as those related to other policies, have been drawn by examining the policy impact on output solely. In particular, it ignores distributional issues and "social justice" which may be at the core of the above sentiment. 


\section{Bibliography}

Bayazitova, Dinara and Anil Shivdasani (2009): "Assessing TARP", Discussion paper, http://ssrn.com/abstract $=1461884$.

Bencivenga, Valerie R., Bruce D. Smith and Ross M. Starr (1996): "Liquidity of secondary capital markets: Allocative efficiency and the maturity", Economic Theory 7, 19-50.

Bental, Benjamin and Benjamin Eden (1993): "Inventories in a Competitive Environment", Journal of Political Economy, Vol. 101(5), pp. 863-886.

Blanchard, Olivier (2009): "The Crisis: Basic Mechanisms, and Appropriate Policies", IMF discussion paper, WP09/80.

Demyanyk, Yuliya and Otto van Hemert (2008): "Understanding the Subprime Mortgage Crisis", Federal Reserve Bank of St. Louis, mimeo;

Dang, Tri Vi, Gary Gorton and Bengt Holmström (2009): "Opacity and the Optimality of Debt for Liquidity Provision", Working Paper.

Diamond, Peter. A. (1965): "National Debt in A Neoclassical Growth Model", The. American Economic Review Vol. 55, pp. 1126-1150.

Goddard, John, Phil Molyneux and John O.S. Wilson (2009): "The financial crisis in Europe: Evolution, Policy Responses and Lessons for the Future", Journal of Financial Regulation and Compliance, Vol. 17(4), pp.362 - 380.

Gorton, Gary B. and Andrew Metrick (2009): "Seruritized Banking and the Run on Repo", NBER Working Paper 15223.

Grossman, Sanford J. and Joseph Stiglitz (1980): "On the Impossibility of Informationally Efficient Markets", American Economic Review, 70(3), pp. 393-408.

Kahle, Kathleen M. and Rene M. Stulz (2010): "Financial Policies and the Financial Crisis: Impaired Credit Channel or Diminished Demand for Capital?", Ohio State University, mimeo.

Lucas, Robert E. Jr. (1978): "Asset Prices in an Exchange Economy," Econometrica, 46, pp 1429-45.

Reinhart, Carmen S. and Kenneth S. Rogoff (2008): "Is the 2007 U.S. SubPrime Financial Crisis So Different? An International Historical Comparison", American Economic Review 98, pp. 339-344. 
Solow, Robert (1956). "A Contribution to the Theory of Economic Growth," Quarterly Journal of Economics, 70, pp. 65-94.

Tirole, Jean (2010): "Overcoming Adverse Selection: How Public Intervention Can Restore Market Functioning", Mimeo.

Uhlig, Harald (2009): "A Model of a Systemic Bank Run", NBER Working Paper No. 15072.

Veronesi, Pietro and Luigi Zingales (2010): "Paulson's Gift", Journal of Financial Economics, Volume 97, Issue 3, pp. 339-368. 
APPENDIX I: Proof of Proposition 2

Given our Cobb-Douglas specification of the production function of new trees, the wage and the marginal product of capital are given by:

$$
\begin{gathered}
\omega(Q(t))=(1-\alpha) A Q(t)^{\alpha} \\
\mu(Q(t))=\alpha A Q(t)^{\alpha-1}
\end{gathered}
$$

Using the specification for the old-tree production $F_{\sigma}(\cdot)$, system $(22)$ becomes:

$$
\left\{\begin{array}{c}
Q(t)+p(t) Q(t-1)=\Lambda(1-\alpha) A Q(t-1)^{\alpha} \\
\frac{\Psi Q(t-1)^{\alpha^{2}-1}}{p(t)}=\alpha A Q(t)^{\alpha-1}+p(t+1)
\end{array}\right.
$$

with $\Lambda=\frac{\beta}{1+\beta}\left[\frac{\lambda}{\gamma}+(1-\lambda)\right]$.

Let $p(t)=\nu Q(t-1)^{\alpha-1}$. Then we obtain:

$$
\left\{\begin{array}{c}
Q(t)+\nu Q(t-1)^{\alpha}=\Lambda(1-\alpha) A Q(t-1)^{\alpha} \\
\frac{\Psi Q(t-1)^{\alpha^{2}-1}}{\nu Q(t-1)^{\alpha-1}}=[\alpha A+\nu] Q(t)^{\alpha-1}
\end{array}\right.
$$

Substituting $Q(t)$ from the first line into the second yields:

$$
\frac{\Psi Q(t-1)^{\alpha^{2}-1}}{\nu Q(t-1)^{\alpha-1}}=[\alpha A+\nu][\Lambda(1-\alpha) A-\nu]^{\alpha-1} Q(t-1)^{\alpha(\alpha-1)}
$$

It is easy to verify that $Q(t-1)$ cancels, so that the above expression implicitly defines $\nu$ in (23) to satisfy:

$$
\Psi=\nu[\alpha A+\nu][\Lambda(1-\alpha) A-\nu]^{\alpha-1}
$$

Finally, $\Omega$ in (24) is given by:

$$
\Omega=\Lambda(1-\alpha) A-\nu .
$$

